\title{
Tuning the morphological properties of cellulose aerogels: an investigation of salt-mediated preparation
}

\author{
Prakash Parajuli $\mathbb{D} \cdot$ Sanjit Acharya $\mathbb{(} \cdot$ Julia L. Shamshina $(\mathbb{C} \cdot$ Noureddine Abidi $\mathbb{C}$
}

Received: 15 March 2021 / Accepted: 16 June 2021/Published online: 29 June 2021

(C) The Author(s) 2021

\begin{abstract}
In this study, alkali and alkaline earth metal chlorides with different cationic radii $(\mathrm{LiCl}$, $\mathrm{NaCl}$, and $\mathrm{KCl}, \mathrm{MgCl}_{2}$, and $\mathrm{CaCl}_{2}$ ) were used to gain insight into the behavior of cellulose solutions in the presence of salts. The specific focus of the study was on the evaluation of the effect of salts' addition on the sol-gel transition of the cellulose solutions and on their ability to form monoliths, as well as the evaluation of the morphology (e.g., specific surface area, pore characteristics, and microstructure) of aerocelluloses prepared from these solutions. The effect of the salt addition on the sol-gel transition of cellulose solutions was studied using rheology, and morphology of resultant aerogels was evaluated by scanning electron microscopy and Brunauer-Emmett-Teller analysis, while the salt influence on the aerocelluloses' crystalline structure and thermal stability was evaluated using powder X-ray diffraction and thermogravimetric analysis, respectively. The study revealed that the effect of salts' addition was dependent on the
\end{abstract}

component ions and their concentration. The addition of salts in the amount below certain concentration limit significantly improved the ability of the cellulose solutions to form monoliths and reduced the sol-gel transition time. Salts of lower cationic radii had a greater effect on gelation. However, excessive amount of salts resulted in the formation of fragile monoliths or no formation of gels at all. Analysis of surface morphology demonstrated that the addition of salts resulted in a significant increase in porosity and specific surface area, with salts of lower cationic radii leading to aerogels with much larger $(\sim 1.5$ and 1.6fold for $\mathrm{LiCl}$ and $\mathrm{MgCl}_{2}$, respectively) specific surface area compared to aerocelluloses prepared with no added salt. Thus, by adding the appropriate salt into the cellulose solution prior to gelation, the properties of aerocelluloses that control material's performance (specific surface area, density, and porosity) could be tailored for a specific application.

P. Parajuli · S. Acharya · J. L. Shamshina · N. Abidi $(\square)$ Fiber and Biopolymer Research Institute, Department of Plant and Soil Science, Texas Tech University, Lubbock, TX 79409, USA

e-mail: noureddine.abidi@ttu.edu 


\section{Graphic abstract}
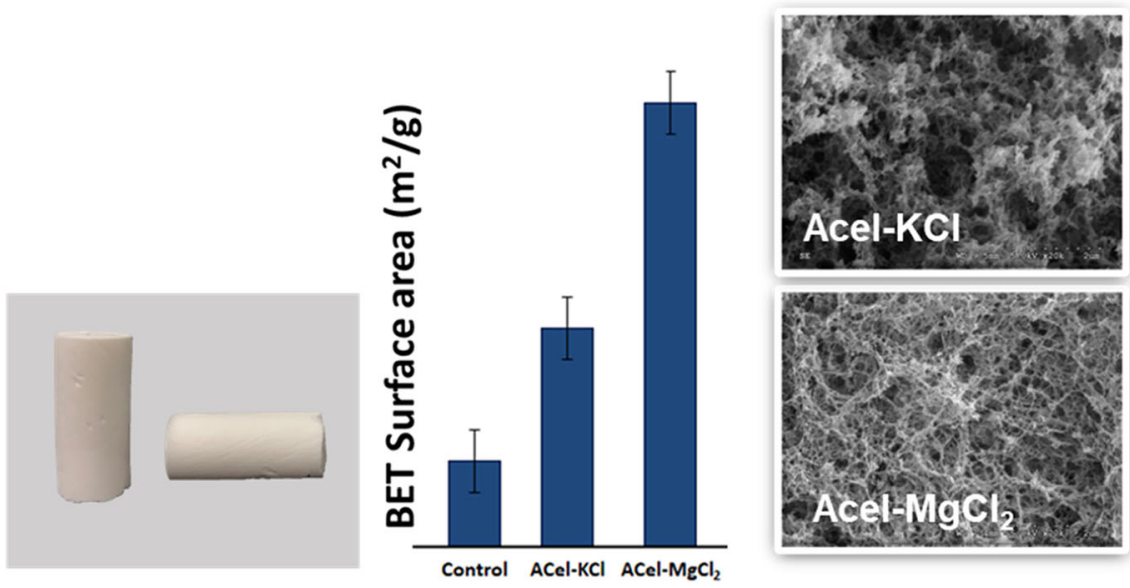

Keywords Cellulose aerogels $\cdot$ Salts $\cdot$ Cationic radii $\cdot$ Morphology $\cdot$ Specific surface area $\cdot$ Porosity

\section{Introduction}

Biodegradable and non-toxic natural polymeric materials have attracted considerable attention in multiple industries in today's world, due to a serious environmental pollution created by synthetic plastics. Among those, eco-friendly and biodegradable cellulose polymer allows to prepare products such as cellulose aerogels which have unique set of properties. Cellulose aerogels (aerocelluloses) represent a special class of cellulose materials with open pore solid networks with high porosity (Budtova 2019), low density and high specific surface area (Gavillon and Budtova 2008). Aerocelluloses are developed through series of steps including cellulose dissolution, gelation, solvent exchange and drying with supercritical $\mathrm{CO}_{2}$ without significant alteration in their network morphology (Budtova 2019). During the process, the solvent inside cellulose gels is replaced with air, creating versatile porous materials that can accommodate air within their pores (Budtova 2019; Budtova and Navard 2016; Long et al. 2018). There is a large collection of other aerogel definitions in recent review by Budtova (Budtova 2019). Due to the attractive properties of cellulose such as renewability, biocompatibility, biodegradability, and chemical stability, and important material characteristics of aerogels such as high specific surface area, low density, and high porosity (Long et al. 2018), aerocelluloses are used for a wide range of applications. Multiple reviews on applications of cellulose aerogels are available elsewhere (Budtova 2019; Cai et al. 2014; Mirtaghavi et al. 2020; Khalil et al. 2020; Garba et al. 2020). The products based on aerocelluloses range from high-value products in pharmaceutical and biotech industries (e.g., drug delivery vehicles, cell storage/growth devices, tissue engineering scaffolds (Pircher et al. 2015; Chin et al. 2016; Cai et al. 2014) to medium- or low-value products (e.g., adsorbents (Dassanayake et al. 2016), oil/water separation agents (Liao et al. 2016), chromatographic systems (Luo and Zhang 2010), catalysts (Schestakow et al. 2016b), heat insulation materials (Lazzari et al. 2019), metal nanoparticle/metal oxide carriers (Wan et al. 2016; Tian et al. 2017), and energy absorbers ( $\mathrm{Li}$ et al. 2018)). For all these applications, the specific surface area, porosity and pore size distribution are undoubtedly the most meaningful morphological characteristics of the materials, as they define the product performance. Thus, the ability to control these intricate aerocelluloses' features is of particular interest.

Properties of aerocelluloses can be tailored by altering different factors or conditions in each step of their preparation: the polymer's dissolution, regeneration (gel formation), and drying. For example, the 
type of solvent system used to dissolve cellulose significantly impacts the morphology of aerocelluloses (Pircher et al. 2016), because of the difference in the arrangement of the cellulose chains in these diverse solvent systems. Similarly, altering the morphology of aerocelluloses could be achieved using various additives (e.g., paraffin spheres as porogen particles (Pircher et al. 2015), oil droplets (Ganesan et al. 2016), and surfactants (Ganesan et al. 2018a) to cellulose solutions prior to gel formation. Antisolvents used during cellulose regeneration (Schestakow et al. 2016a) and drying conditions such as supercritical drying, fast- or slow-freezing lyophilization also considerably affect internal aerocelluloses' structure (Buchtová and Budtova 2016).

While studies regarding the effects of various factors on the aerocellulose properties have been carried out, there is no systematic study on the effect of the use of inorganic salt additives on the sol-gel transition of the cellulose solution and the morphology of the resulting aerocelluloses' structure. Indeed, understanding the interaction between inorganic salts and cellulose is not inconsequential. It helps discover the mechanistic role of salt in controlling rheological properties of cellulose solutions, manipulating the physicochemical (including morphological) properties of subsequently regenerated cellulose, and better controlling the conversion of cellulose solutions into useful value-added products (Zhang et al. 2019).

A handful of studies have been reported on the ability of inorganic salts to alter the properties of cellulose solutions resulting in a subsequent change of aerogel properties. Wei and Wang studied the effect of inorganic salts on the gelation of cellulose solution (Wei and Wang 2013). They reported incremental increase in the gelation rate with the salt dosage and in the order $\mathrm{K}^{+}>\mathrm{Na}^{+}>\mathrm{Li}^{+}$for salt cations, and $\mathrm{Cl}^{-}$ $>\mathrm{Br}^{-}>\mathrm{NO}_{3}{ }^{-}$for anions. Similarly, Laka et al. reported that cations of inorganic salts promoted while anions hindered cellulose gel formation, and that the effect was dependent on the metal valency and salt concentration (Laka et al. 2001). Tokuyasu et al. reported that cellulose pretreatment with calcium chloride $\left(\mathrm{CaCl}_{2}\right)$ increased the surface area of aerogels (Tokuyasu et al. 2008). It has also been shown that trivalent inorganic salts were more effective in degrading polysaccharide molecules, followed by divalent, and monovalent salts (Liu et al. 2009; Kang et al. 2013). Phan-Xuan et al. studied the effect of the valences of the ions on the aggregation behavior and colloidal stability of aqueous cellulose nanocrystals (CNCs) and determined that the salts of multivalent (divalent and trivalent) ions were more effective in inducing CNC aggregation than those of monovalent ions (Phan-Xuan et al. 2016).

In our previous study, we investigated the effect of the addition of sodium chloride $(\mathrm{NaCl})$ salt on aerocellulose properties and found that the addition of $5 \mathrm{wt} \%$ of $\mathrm{NaCl}$ resulted in an increase of the specific surface area by $\sim$ two-fold, and a slight increase in the porosity of cellulose aerogels (Parajuli et al. 2020). In this work, we hypothesized that the addition of various inorganic salts (mono- and divalent, of different cationic radii) would affect the sol-gel transition of cellulose solutions, and, therefore, provide the opportunity to tune the microarchitecture (specific surface area, pore size, total pore volume, and pore size distribution) of the resulting aerocelluloses in a predictable manner, with a microstructure of aerocelluloses being a function of the salt's cation.

In this paper, we report a systematic study of the effect of monovalent $(\mathrm{LiCl}, \mathrm{NaCl}$, and $\mathrm{KCl})$ and divalent salts $\left(\mathrm{CaCl}_{2}\right.$ and $\left.\mathrm{MgCl}_{2}\right)$ on the specific surface area, pore characteristics, and other microstructural attributes of cellulose aerogels. We also discuss the effect of salt addition on the sol-gel transition of cellulose solutions which, we believe, has a significant impact on the physicochemical properties of aerocelluloses.

\section{Experimental}

\section{Materials}

Microcrystalline cellulose (MCC) (with degree of polymerization (DP) 180) (Avicel (C) PH 102) was purchased from FMC Biopolymer (Newark, DE, USA). Sulfuric acid $\left(\mathrm{H}_{2} \mathrm{SO}_{4}, \geq 95 \%\right)$, sodium hydroxide pellets $(\mathrm{NaOH}, \geq 98 \%)$, and powdered inorganic salts - sodium chloride $(\mathrm{NaCl}, \geq 99 \%)$, potassium chloride $(\mathrm{KCl}, \geq 99 \%$ ), lithium chloride ( $\mathrm{LiCl}, 99 \%)$, calcium chloride $\left(\mathrm{CaCl}_{2}, 96 \%\right)$, and magnesium chloride $\left(\mathrm{MgCl}_{2}, \geq 99 \%\right)$ were purchased from Sigma Aldrich (Saint Louis, MO, USA) and used as received. Cylindrical glass vials $(12 \mathrm{~mL}$, outer diameter (OD) $21 \times 50 \mathrm{~mm}$ ) purchased from DWK Life Sciences (Millville, NJ, USA) were used as mold. 
Acetone $(\geq 98 \%)$ was purchased from Fisher Scientific (Pittsburgh, PA, USA) and used as received. Compressed $\mathrm{CO}_{2}$ (Bone Dry 3.0) was purchased from Airgas (Ft. Worth, TX, USA). Deionized (DI) water was obtained from AquaOne (Amarillo, TX, USA).

Methods

\section{Preparation of MCC solutions}

MCC was used as a precursor for aerocellulose preparation. Cellulose solutions ( $5 \mathrm{wt} \%$ cellulose) were prepared as followed. First, $\mathrm{NaOH}_{\mathrm{aq}}$ was prepared by mixing $7.6 \mathrm{~g} \mathrm{NaOH}$ (solid) in $37.4 \mathrm{~mL}$ DI water and pre-cooled at $-12{ }^{\circ} \mathrm{C}$ for $2 \mathrm{~h}$. Simultaneously, MCC dispersion was prepared by mixing $5 \mathrm{~g}$ of MCC powder in $50 \mathrm{~mL}$ water, and also precooled at $5{ }^{\circ} \mathrm{C}$ for $2 \mathrm{~h}$. Then, these two solutions were mixed and stirred at $500 \mathrm{rpm}$, to result in $\mathrm{NaOH}_{\mathrm{aq}}-$ cellulose solution with an overall concentration of 7.6 wt $\% \mathrm{NaOH}$, and $5 \mathrm{wt} \% \mathrm{MCC}$. The resultant translucent solution was stored at $-12{ }^{\circ} \mathrm{C}$ for $1 \mathrm{~h}$ while stirring every $5 \mathrm{~min}$ for $30 \mathrm{~s}$. Exact amounts of solid salts ( $\mathrm{LiCl}, \mathrm{NaCl}, \mathrm{KCl}, \mathrm{MgCl}_{2}$, and $\mathrm{CaCl}_{2}$ ) were added into the fixed volume of the $\mathrm{NaOH}_{\mathrm{aq}}$-cellulose solution to prepare solutions of different salt concentrations (w/w), namely, 0 (control), 0.5, 1, 3, 5, 7, and $10 \mathrm{wt} \%$, and stirred at $300 \mathrm{rpm}$ at $5{ }^{\circ} \mathrm{C}$ for $5 \mathrm{~min}$.

\section{Rheological properties of the cellulose solution}

The rheological properties of cellulose solutions with no salt added (control) and with $0.5 \mathrm{wt} \%$ salts were measured to investigate the effect of salts on the solgel transition of cellulose solutions using a rheometer with a $40 \mathrm{~mm}$ circular plate geometry and a Peltier temperature control system (AR 2000EX, TA Instruments, New Castle, DE, USA). A small volume (ca. $5 \mathrm{~mL}$ ) of the solution was used for the measurement, and the rest was used for aerogel preparation. Two types of measurements, time sweep test and temperature sweep test, were performed according to the previously reported method with slight modifications (Oğuz and Ege 2018). The time sweep test was performed at a constant temperature of $20{ }^{\circ} \mathrm{C}$ and an angular frequency of $6.28 \mathrm{rad} / \mathrm{s}$. The temperature sweep test was performed at an angular frequency of $6.28 \mathrm{rad} / \mathrm{s}$ in the temperature range of $20-40{ }^{\circ} \mathrm{C}$. Dynamic viscoelastic parameters, the shear storage modulus $\left(\mathrm{G}^{\prime}\right)$ and loss modulus $\left(\mathrm{G}^{\prime \prime}\right)$, were measured as a function of time $(\mathrm{t}, \mathrm{s})$ and temperature $\left(\mathrm{T},{ }^{\circ} \mathrm{C}\right)$ to evaluate the sol-gel transition behavior of cellulose solutions in the presence of different salts. The point of gelation was taken when $\mathrm{G}^{\prime}=\mathrm{G}^{\prime \prime}$ (Cai and Zhang 2006).

\section{Preparation of aerogels}

Cellulose aerogels ( $5 \mathrm{wt} \%$ cellulose) were prepared using the sol-gel-drying route using the approach reported previously (Dassanayake et al. 2016). The pure cellulose and cellulose/salt solutions (see above) were poured into $12 \mathrm{~mL}$ cylindrical vials, capped with parafilm and subsequently gelled at $50{ }^{\circ} \mathrm{C}$ for $2 \mathrm{~h}$ to form a solid gelled mass. The resultant cylindrical gels were regenerated and washed in DI water until the initially yellow hydrogels became completely white. DI water was exchanged every $30 \mathrm{~min}$ throughout the day (ca. 15-20 times). After that, the regenerated hydrogels were neutralized in $0.1 \mathrm{M} \mathrm{H}_{2} \mathrm{SO}_{4}$ for $24 \mathrm{~h}$. Afterward, the cellulose hydrogels were successively rinsed with DI water several times (ca. 10-15 times) before supercritical drying.

\section{Supercritical drying}

The supercritical drying process was accomplished using Critical Point Dryer (SPI-Dry jumbo, SPT Supplies, West Chester, PA, USA) equipped with a water jacket for heating and cooling following the protocol described previously (Gavillon and Budtova 2008). Aerogel precursors were prepared by replacing the water inside the hydrogel with acetone. Cellulose hydrogels formed by regenerating cellulose solutions were immersed in pure acetone, and acetone was exchanged every two hours throughout the day for four days to ensure that water inside hydrogels was completely replaced by acetone. Vials with acetonefilled hydrogels were placed into the chamber of the critical point dryer filled with liquid $\mathrm{CO}_{2}$ and kept immersed for $48 \mathrm{~h}$ with $\mathrm{CO}_{2}$ flushing every $30 \mathrm{~min}$. After $48 \mathrm{~h}$, the temperature was set above the critical points of $\mathrm{CO}_{2}$. After the required temperature and pressure (1 L autoclave, $80 \mathrm{~atm}, 35^{\circ} \mathrm{C}$ ) (Gavillon and Budtova 2008) were reached, the dryer was slowly depressurized ( $4 \mathrm{~atm} / \mathrm{h}$ ), and cellulose aerogels were recovered from the chamber. Aerogels developed with $\mathrm{LiCl}, \mathrm{NaCl}, \mathrm{KCl}, \mathrm{MgCl}_{2}$, and $\mathrm{CaCl}_{2}$ were labeled as 
ACel-LiCl, ACel-NaCl, ACel-KCl, ACel- $\mathrm{MgCl}_{2}$, and $\mathrm{ACel}-\mathrm{CaCl}_{2}$, respectively, whereas the aerogel without any salt was labeled as 'control'. Aerogels were prepared in triplicates for each salt of every concentration.

\section{Material characterization}

\section{Density and porosity determination}

Geometric dimensions of the aerocelluloses were measured using a digital caliper, whereas the weight was determined gravimetrically. The density of the monoliths was determined using their geometric dimensions and weight values. The porosity was calculated using the following equation (Sehaqui et al. 2011):

Porosity $=1-\left(\frac{\rho_{\mathrm{a}}}{\rho_{\mathrm{c}}}\right)$

where $\rho_{\mathrm{a}}=$ density of aerogels $\left(\mathrm{g} / \mathrm{cm}^{3}\right), \rho_{\mathrm{c}}=$ density of cellulose $\left(\mathrm{g} / \mathrm{cm}^{3}\right), \rho_{\mathrm{a}} / \rho_{\mathrm{c}}=$ relative density.

\section{Surface area and pore characteristics analysis}

The Brunauer-Emmet-Teller (BET) surface area $\left(\mathrm{S}_{\mathrm{BET}}\right)$, total pore volume, and the pore characteristics of aerogels were determined from $\mathrm{N}_{2}$ adsorptiondesorption isotherms collected using surface area analyzer (Gemini VII 2390, Micromeritics, Norcross, GA, USA) at $-196{ }^{\circ} \mathrm{C}$ in a liquid nitrogen environment. Prior to measurements, each sample was degassed at $120{ }^{\circ} \mathrm{C}$ for $18 \mathrm{~h}$ under a continuous flow of $\mathrm{N}_{2}$. The surface area was evaluated using the BET method (Brunauer et al. 1938), while the cumulative pore volume and the pore size distribution were determined using Barret-Joyner-Halendar (BJH) method (Barrett et al. 1951).

\section{Surface morphology}

The morphology of aerocelluloses was characterized using a field emission scanning electron microscope (FESEM) (S/N 4300, Hitachi, Chiyoda, Tokyo, Japan). Cellulose aerogel monoliths were cut open with a sharp blade to reveal their internal structure and a small piece was fixed onto the sample holder with double-sided carbon tape. The samples were coated by iridium of $2-3 \mathrm{~nm}$ thickness and images were recorded using the microscope at $5 \mathrm{kV}$ accelerating voltage. The images were analyzed using Quartz PCI Imaging software (Version 8, Quartz Imaging Corp., Vancouver, Canada) (https://www.quartzimaging. com/pci-microscope-imaging-software.html).

\section{Crystallinity}

The crystalline structures were identified using the powder X-ray diffraction (pXRD) technique on SmartLab system (HD 2711 N, Rigaku Corp., Tokyo, Japan) using $\mathrm{CuK} \alpha$ radiation $(\lambda=1.54 \AA$ ) $)$ generated at a voltage of $40 \mathrm{kV}$, and current of $44 \mathrm{~mA}$ at a scan rate of $1 \% \mathrm{~min}$, from $5^{\circ} 2 \theta$ to $50^{\circ} 2 \theta$. Samples were placed on a glass slide holder and the diffractogram of the empty glass slide was first recorded and subtracted from the diffractogram of the sample. The crystallinity index (CI) was calculated using the following equation (Segal et al. 1959; Nam et al. 2016):

$C I=\left[\frac{\left(I_{t}-I_{a}\right)}{I_{t}}\right] * 100$

where $I_{t}$ represents the intensity of the $\left(\begin{array}{lll}0 & 2 & 0\end{array}\right)$ peak at $2 \theta=21.7^{\circ}$, while Ia represents the amorphous intensity of the peak at $2 \theta=16^{\circ}$ as reported previously for cellulose II (Nam et al. 2016).

Similarly, the crystallite size was calculated using the Scherrer Eq. (3) (Scherrer 1912).

$\beta=\frac{K \lambda}{L \cos \theta}$

where $\beta$ is the crystallite size perpendicular to the lattice plane represented by $(1-10), K$ is the Scherrer constant for a given crystal shape $(K=0.9), \lambda$ represents the wavelength of the incident X-rays (1.54 $\AA$ ), $L$ represents the width of the peak at half of its maximum, in radians (FWHM), and $\theta$ is the position of the peak (half of the plotted $2 \theta$ value) (French and Cintron 2013).

\section{Thermal properties}

Thermal properties were examined using Thermogravimetric Analyzer (TGA) (Pyris1, PerkinElmer Inc., Shelton, CT, USA) under a nitrogen flow of $20 \mathrm{~mL} / \mathrm{min}$ and heating rate of $10{ }^{\circ} \mathrm{C} / \mathrm{min}$ ranging from 37 to $600{ }^{\circ} \mathrm{C}$. The thermograms were analyzed using Pyris software (version 11, PerkinElmer Inc., 
Shelton, CT, USA) (www.perkinelmer.com/product/ s-w-kit-pyris-standard-single-user-n5340092) by calculating the first derivatives of the thermograms (DTG), weight loss percentage, and decomposition temperatures.

\section{Statistical analysis}

One-way analysis of variance (ANOVA) was performed with salts as a factor to determine the statistical difference between the means of the independent variables, for surface area tests and pore characteristics (diameter, density, total pore volume, and porosity). All the analyses were conducted using STATISTICA (Version 13, TIBCO Software Inc., Palo Alto, CA, USA) (https://docs.tibco.com/ products/tibco-statistica-13-3-0) at 95\% confidence interval (CI). Three independent replications for each sample were performed.

\section{Results and discussion}

Tendency of cellulose solution to form intact monoliths in the presence of different salts

For the formation of gels, similarly to our previous publication (Parajuli et al. 2020), dissolution of commercial MCC in $\mathrm{NaOH}_{\text {aq }}$ solvent system was conducted. Cylindrical vials $(12 \mathrm{~mL})$ with an inner diameter (I.D) of $17 \mathrm{~mm}$, and a height of $50 \mathrm{~mm}$ (KIMBLE® OPTICLEAR Clear Glass Vial, Catalog number $60975 \mathrm{~L}-3$ ) were used as molds, to which $10 \mathrm{~mL}$ of solution was added resulting in a height of the solution 44-45 mm. In order to prepare a 'control' aerocellulose, dissolution of commercial MCC (5 $\mathrm{wt} \%$ ) in $7.6 \mathrm{wt} \% \mathrm{NaOH}_{\mathrm{aq}}$ solvent system with no added salt was carried out through several freeze/thaw (F/T) cycles [see the Experimental Section for details (Dassanayake et al. 2016)], followed by gelation at $50{ }^{\circ} \mathrm{C}$, solvent exchange and supercritical drying. Pure MCC solution yielded monoliths upon regeneration, indicated by the change in color of the cellulose gels from yellowish to white, and remained intact during subsequent processes until drying. Supercriticallydried control aerogels were white, and looked compact, with a smooth surface (Fig. 1, left).

When the solid salts $(0.5 \mathrm{wt} \%$ of $\mathrm{LiCl}, \mathrm{NaCl}, \mathrm{KCl}$, $\mathrm{MgCl}_{2}$, and $\mathrm{CaCl}_{2}$ ) were introduced to the polymer's solution prior to the gelation stage (see "Experimental" section), and solutions were gelled and supercritically-dried in the same manner as the control, aerogels obtained with added salt were of the same white color. Despite the same amount of MCC used for the preparation, aerocelluloses prepared with added monovalent salts appeared bigger in size than the control sample, following the trend $\mathrm{ACel}-\mathrm{KCl}>$ ACel-NaCl $>$ ACel-LiCl $>$ control (Fig. 1). Interestingly, the aerocellulose prepared with added $\mathrm{CaCl}_{2}$ looked somewhat bigger than the control and the one prepared with $\mathrm{MgCl}_{2}$ appeared comparable to the control (Fig. 1), and in terms of size ACel- $\mathrm{CaCl}_{2-}$ $>\mathrm{ACel}-\mathrm{MgCl}_{2} \sim$ control. Aerogels prepared with added salt were somewhat less compact and were softer and weaker by pinch testing than the control. Similar to our previous publication (Parajuli et al. 2020), the volume shrinkage was observed for all hydrogels.

Examining maximum amounts of solid salts $(\mathrm{LiCl}$, $\mathrm{NaCl}, \mathrm{KCl}, \mathrm{MgCl}_{2}$, and $\mathrm{CaCl}_{2}$ ) that could be introduced into the polymer's solution prior to the gelation stage, we found out that each salt had its own concentration limit for producing a stable structure during regeneration, and showed different tendencies to form monoliths, see Table 1 . The maximum salt concentration that could be incorporated into cellulose solutions and yielded strong monoliths upon regeneration and drying was increasing in the order: $\mathrm{CaCl}_{2}(1$ $\mathrm{wt} \%)<\mathrm{MgCl}_{2}(3 \mathrm{wt} \%)<\mathrm{KCl}(5 \mathrm{wt} \%)<\mathrm{NaCl}(7$ $\mathrm{wt} \%)<\mathrm{LiCl}(10 \mathrm{wt} \%)$.

Though the cellulose gels with slightly higher salt load (3 wt $\% \mathrm{CaCl}_{2}, 5 \mathrm{wt} \% \mathrm{MgCl}_{2}, 7 \mathrm{wt} \% \mathrm{KCl}$ ) remained intact during regeneration and drying, they were fragile and would break easily during handling and pinch testing. Cellulose gels with salt concentrations higher than the concentration limit could not be regenerated but were instead gradually "washed away" with water during several steps of solvent exchange; monoliths were never formed. (Note that the maximum attempted concentration for $\mathrm{LiCl}$ was 10 $\mathrm{wt} \%$, that resulted in firm stable aerogel and no concentrations exceeding $10 \mathrm{wt} \%$ was attempted.)

This trend shows that the tendency to form monolith decreased with an increase in cationic radii for monovalent and divalent salts following the order $\mathrm{Li}^{+}>\mathrm{Na}^{+}>\mathrm{K}^{+}$and $\mathrm{Mg}^{2+}>\mathrm{Ca}^{2+}$. The observed phenomenon directly corresponds to the Hofmeister series where the surface affinity of the cations 


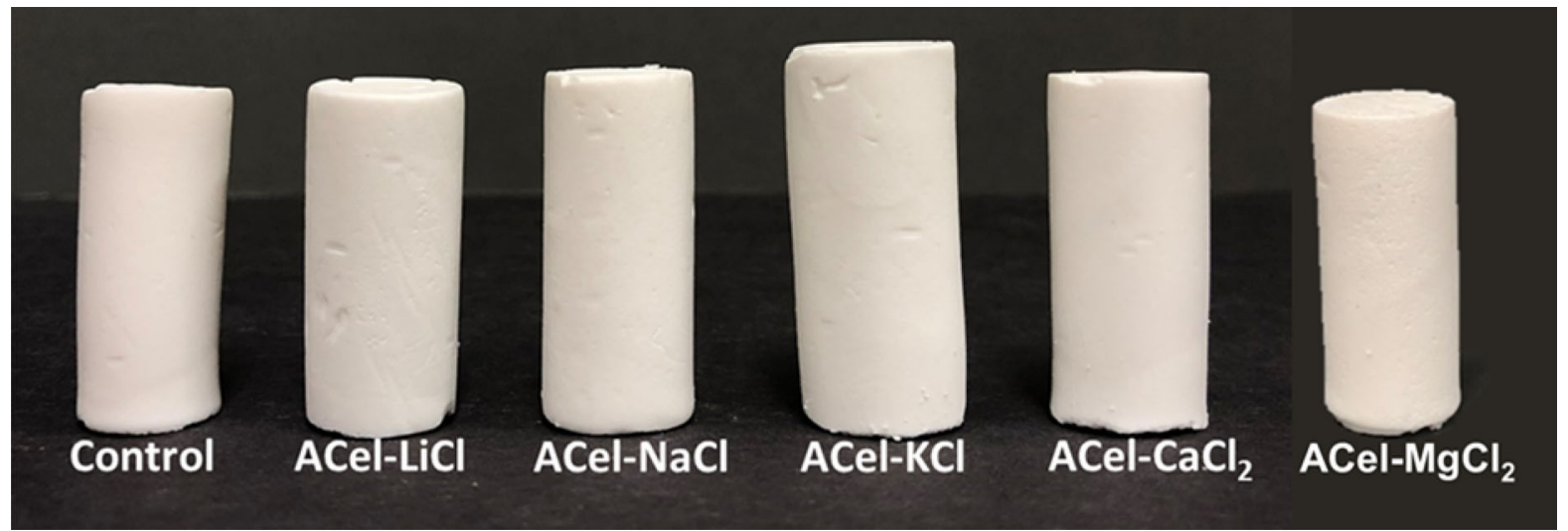

Fig. 1 Cellulose aerogels developed without salt (control) and with salts (note increase in all dimensions with an increase of cationic radii)

Table 1 Ability to form cellulose gels during regeneration in the presence of different salts

\begin{tabular}{|c|c|c|c|c|c|c|}
\hline \multirow[t]{2}{*}{ Salts } & \multicolumn{6}{|c|}{ Salt Concentration, wt $\%$} \\
\hline & 0.5 & 1 & 3 & 5 & 7 & 10 \\
\hline $\mathrm{LiCl}$ & $+{ }^{a}$ & + & + & + & + & + \\
\hline $\mathrm{NaCl}$ & + & + & + & + & + & $+/{ }^{\mathrm{b}}$ \\
\hline $\mathrm{KCl}$ & + & + & + & + & $+1-$ & - \\
\hline $\mathrm{MgCl}_{2}$ & + & + & + & $+1-$ & - & - \\
\hline $\mathrm{CaCl}_{2}$ & + & + & $+1-$ & $-{ }^{\mathrm{c}}$ & - & - \\
\hline
\end{tabular}

${ }^{\mathrm{a}}$ Monolith formed $(+)$ - stable/strong monoliths were obtained after drying; ${ }^{\mathrm{b}}$ Fragile monolith $(+/-)-$ stable structure was formed after regeneration but was destroyed during drying; ${ }^{c}$ Monolith did not form (-) - cellulose did not form stable structure during regeneration

decreases in the order $\mathrm{Li}^{+}>\mathrm{Na}^{+}>\mathrm{K}^{+}$and $\mathrm{Mg}^{2+}$ $>\mathrm{Ca}^{2+}$ (Phan-Xuan et al. 2016). This suggests that a given volume of cellulose solution can hold a higher amount of monovalent salt compared to divalent salt. Moreover, it can also hold a higher amount of salts having a smaller cationic radius than a larger cationic radius without impacting its ability to form a monolith.

Such difference in the tendency of the solution to form a monolith could be due to the effect of the salt on the aggregation rate of the colloidal particles (Woehl et al. 2014). Salts with smaller cationic radii probably induced smaller aggregates than those with larger cationic radii and these aggregates are easily held together through extensive hydrogen bonding. In the latter case, larger-sized aggregates are formed which are difficult to hold together thereby negatively impacting the formation of a monolith during regeneration. Additionally, the difference in the cationic charge might have resulted in altered charge distribution in the solution and therefore, could alter their tendency to form monoliths (Wang et al. 2017). Overall, this showed that the size of component ions and their concentration in solution significantly affected the tendency of cellulose solution to form intact monolith.

Effects of added salts on the sol-gel transition of the cellulose solution

The effect of addition of metal salts on the polymer association in cellulose $/ \mathrm{NaOH}_{\mathrm{aq}}$ solutions and sol-gel transition was investigated using rheological measurements, by following the evolution of storage $\left(\mathrm{G}^{\prime}\right)$ and loss modulus $\left(\mathrm{G}^{\prime \prime}\right)$. The maximum concentration that allowed the formation of monolith during regeneration for all salts used in the study was $1 \mathrm{wt} \%$ (Table 1). However, since few cellulose solutions with $1 \mathrm{wt} \%$ salt concentration formed gels immediately, solutions of smaller concentration, $0.5 \mathrm{wt} \%$, were used for rheological (and all subsequent) studies. The critical gel point in relation to the salt types was determined using Winter and Chambon's theory (Winter and Chambon 1986), which states that the crossover point of storage modulus $\left(\mathrm{G}^{\prime}\right)$ and loss modulus $\left(\mathrm{G}^{\prime \prime}\right)$ represents the gel point (Tung and Dynes 1982).

The evolution of $\mathrm{G}^{\prime}$ and $\mathrm{G}^{\prime \prime}$ as a function of time for cellulose/salt solution at constant $20{ }^{\circ} \mathrm{C}$ temperature is shown in Fig. 2a. Overall, the pure cellulose solution 

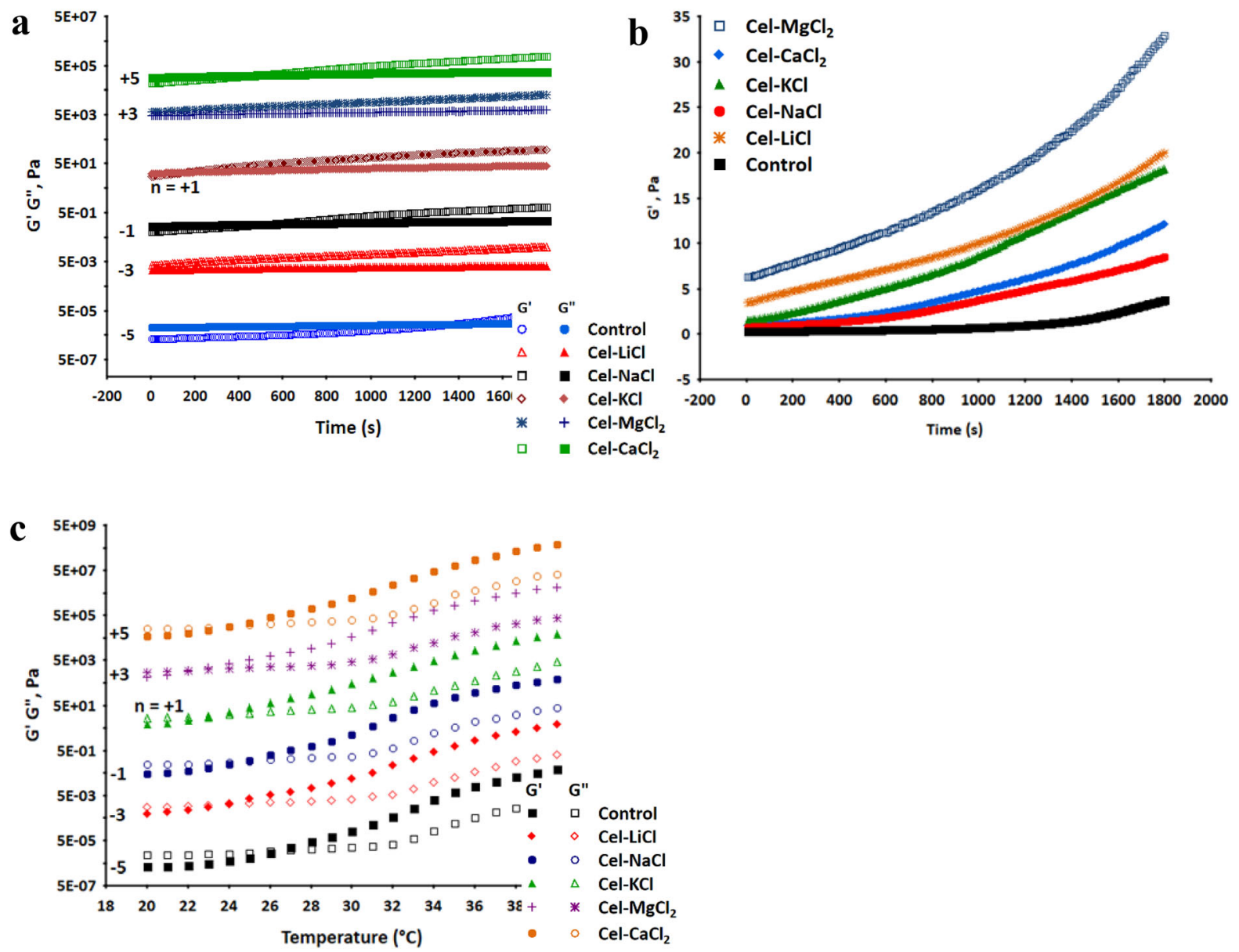

Fig. 2 Effect on salt types on the sol-gel transition of cellulose solution: a time sweep test, b evolution of G' as a function of salt types, c temperature sweep test. The data are shifted along the vertical axis by $10^{\mathrm{n}}$ to avoid overlapping in $(\mathbf{a}, \mathbf{c})$

(control) and cellulose/salt solutions displayed similar rheological behavior. Initially, the $\mathrm{G}^{\prime}$ values of all solutions were smaller than the $\mathrm{G}^{\prime \prime}$ values, indicating a viscous fluid behavior. With time, both $\mathrm{G}^{\prime}$ and $\mathrm{G}^{\prime \prime}$ increased steadily, although the rate of increase was faster for $G^{\prime}$ than $G^{\prime \prime}$. Eventually, $G^{\prime}$ intersected $G^{\prime \prime}$, and the crossover point was observed indicating that the fluid has transitioned from fluid flow-like behavior to solid elastic behavior. This suggested that the solgel transition in pure cellulose solution and cellulose/ salt solutions was a function of time and the system gradually transformed from a viscous liquid into an elastic network of cellulose chains forming a 3Dentangled polymeric network. The sol-gel transition of the cellulose solution indicated that the inclusion complex that was formed between cellulose and solvent molecules during the dissolution got broken, and hydrogen bonds between the polymer chains were re-established (Li et al. 2015).

The critical gel point of the pure cellulose solution was $\sim 1380 \mathrm{~s}$ at $20^{\circ} \mathrm{C}$, which was similar to the previously reported value $(\sim 1200 \mathrm{~s})$ for $5 \mathrm{wt} \%$ cellulose/8 wt $\% \mathrm{NaOH}_{\mathrm{aq}}$ solution (Sescousse et al. 2011). Compared to pure cellulose solution, the critical gel point of cellulose/salt solutions occurred at much shorter time (Table 2, Fig. 2a). Namely, the Cel- $\mathrm{NaCl}$ gelled in about $600 \mathrm{~s}, \mathrm{Cel}-\mathrm{CaCl}_{2}$ in about $540 \mathrm{~s}, \mathrm{Cel}-\mathrm{KCl}$ took about $180 \mathrm{~s}$ to form a gel, while Cel-LiCl and Cel- $\mathrm{MgCl}_{2}$ gelled immediately and stayed as gels during the measurements (Fig. 2a). Furthermore, the initial $\mathrm{G}^{\prime}$ and $\mathrm{G}^{\prime \prime}$ of the Cel- $\mathrm{MgCl}_{2}$ were of much higher values than for other solutions (Fig. 2b). This might have indicated stronger intermolecular forces and higher cellulose chain 
Table 2 Gelation time and temperature of cellulose/salt solution mixtures and salts' cationic radii

\begin{tabular}{|c|c|c|c|c|}
\hline & $\begin{array}{l}\text { Salt's cationic radii (pm) (Shannon 1976; } \\
\text { Ling et al. 2013) }\end{array}$ & $\begin{array}{l}\text { Gelation } \\
\text { time }(\mathrm{s})\end{array}$ & $\begin{array}{l}\text { Gelation } \\
\text { temperature }\left({ }^{\circ} \mathrm{C}\right)\end{array}$ & $\begin{array}{l}\text { Hydration radii of salts' cations (pm) } \\
\text { (Volkov et al. 1997) }\end{array}$ \\
\hline Control & - & 1380 & $\sim 27$ & \\
\hline $\begin{array}{l}\text { Cel- } \\
\mathrm{LiCl}\end{array}$ & 90 & 0 & $\sim 23$ & 382 \\
\hline $\begin{array}{l}\text { Cel- } \\
\mathrm{NaCl}\end{array}$ & 116 & 560 & $\sim 24$ & 358 \\
\hline Cel-KCl & 152 & 159 & $\sim 23$ & 331 \\
\hline $\begin{array}{l}\text { Cel- } \\
\qquad \mathrm{MgCl}_{2}\end{array}$ & 86 & 0 & $\sim 22$ & 428 \\
\hline $\begin{array}{l}\text { Cel- } \\
\mathrm{CaCl}_{2}\end{array}$ & 114 & 519 & $\sim 24$ & 412 \\
\hline
\end{tabular}

entanglement (Long et al. 2019) in the case of Cel$\mathrm{MgCl}_{2}$. Overall, the critical gel point was found to follow the order: control $>\mathrm{Cel}-\mathrm{NaCl}>\mathrm{Cel}-\mathrm{CaCl}_{2}$ $>\mathrm{Cel}-\mathrm{KCl}>\mathrm{Cel}-\mathrm{LiCl} \sim \mathrm{Cel}-\mathrm{MgCl}_{2}$. This supported earlier observation that salts had accelerating effect on the gelation, but came to be against earlier determined trend $\left(\mathrm{K}^{+}>\mathrm{Na}^{+}>\mathrm{Li}^{+}\right.$(Wei and Wang 2013)) likely due to the use of different solvent system.

It was also observed that the addition of salts slightly reduced the sol-gel transition temperature of the cellulose solution (Table 2, Fig. 2c). The pure cellulose solution gelled at about $27^{\circ} \mathrm{C}$, whereas all the cellulose/salt solution mixtures gelled at lower temperatures. Cel- $\mathrm{NaCl}$ and $\mathrm{CaCl}_{2}$ gelled at $24{ }^{\circ} \mathrm{C}$, followed by $\mathrm{Cel}-\mathrm{LiCl}$ and $\mathrm{Cel}-\mathrm{KCl}$ that gelled at $23{ }^{\circ} \mathrm{C}$, and Cel- $\mathrm{MgCl}_{2}$ that gelled at $22{ }^{\circ} \mathrm{C}$.

Although this decrease in the sol-gel transition temperature due to salt addition was not significant, the strategy could be useful in applications where lowering of sol-gel transition temperature is desired, for instance, in drug delivery applications (Joshi 2011). It should be noted, however, that the hydrogels formed under these conditions (time and temperature) were fragile and could easily break under stress (Gavillon 2007). Therefore, during aerogel preparation, higher temperatures $\left(50^{\circ} \mathrm{C}\right)$ and longer time $(2 \mathrm{~h})$ were selected for gels formation to prepare stronger monoliths and avoid breakage during subsequent handling.
Density and porosity

The porosity values of cellulose aerogel monoliths as a function of salt treatments is shown in Fig. 3. It could be seen from the graphs that the addition of salts had a significant effect on the porosity of aerogels.

The control sample had a significantly lower porosity $(88.3 \%)$ than all other aerocelluloses. Among samples prepared with added salts, the porosity followed the trend (note that here " $>$ "-sign indicated statistically significant difference): $\mathrm{Cel}-\mathrm{KCl}$ $(92.5 \%)>\mathrm{ACel}_{-} \mathrm{CaCl}_{2} \quad(90.5 \%) \sim \mathrm{ACel}-\mathrm{NaCl}$ $(90.3 \%) \sim \mathrm{ACel}-\mathrm{LiCl} \quad(90.1 \%) \sim \mathrm{ACel}-\mathrm{MgCl}_{2}$ $(89.4 \%)$. The opposite trend was observed for density, with $\mathrm{ACel}-\mathrm{MgCl}_{2}$ possessing the highest density $(0.15$ $\left.\mathrm{gm} / \mathrm{cm}^{3}\right)$, and ACel- $\mathrm{KCl}$ the lowest one $\left(0.11 \mathrm{gm} / \mathrm{cm}^{3}\right)$ (data not shown). The higher porosity achieved with added salt could be attributed to the restriction in the normal reorganization of cellulose chains due to the interaction between cellulose and cations of the salts in the solutions during the regeneration process.

\section{Scanning electron microscopy (SEM)}

The internal morphology of the aerogels was studied by SEM. SEM images of the cross-sections of the monoliths are shown in Fig. 4. All aerogel samples exhibited porous structures with inner morphology strongly affected by salt addition. Control aerogel exhibited compact structure compared to more open porous structure for aerogels prepared with added salt. The latter group had a fine fibrillated texture, which gave aerogels a porous appearance of the cross- 


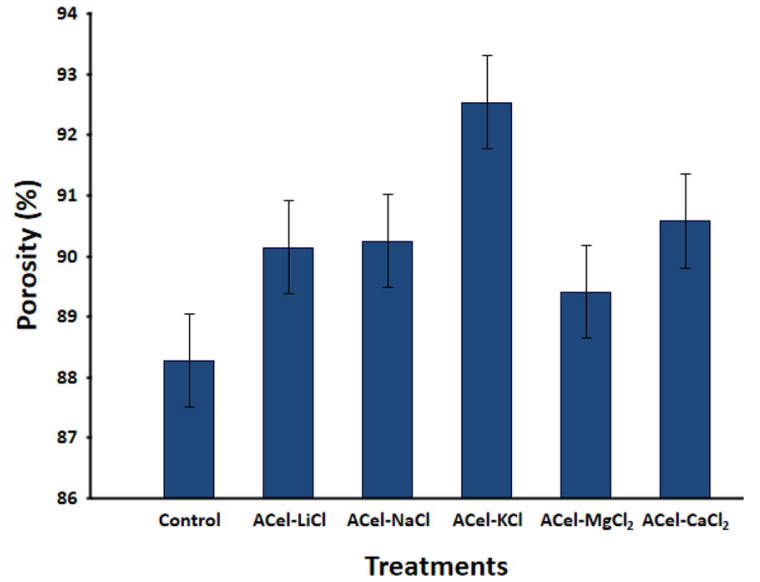

Fig. 3 Effect of salts on the porosity of aerocelluloses

sections (Sescousse et al. 2011). Specifically, a denser arrangement of the fibrils and a higher number of smaller pores could be observed in $\mathrm{ACel}-\mathrm{MgCl}_{2}$ and $\mathrm{ACel}-\mathrm{LiCl}$, whereas more expansive open spaces were observed in $\mathrm{ACel}-\mathrm{KCl}$ (see insets in Fig. 4); the pores of various sizes were observed in each of the samples (see cumulative pore volume, below).

The observed difference in the inner morphology could be attributed to the variation in the nature of the precursor sol induced by the addition of different salts. The nature of salts likely affected the properties of the cellulose solution which in turn influenced the phase separation process of the cellulose during regeneration and determined the micromorphology of the aerogels. The cellulose solution presumably underwent microphase separation during the gel formation leading to cellulose-poor and cellulose-rich phases (Gavillon and Budtova 2008). During the phase separation process, cellulose chains aggregated rapidly to form gels, and the presence of salt hydrates interfered with the normal aggregation process leading to differences in morphology. However, in the case of ACel- $\mathrm{KCl}$ and ACel$\mathrm{NaCl}$, despite their significant differences in the porosity values, no significant differences were observed in SEM images that could be caused by iridium. It has been reported that the coating might alter the interconnected regenerated cellulose network (Juhasz et al. 2021) inducing what is called "false morphology".

Nitrogen adsorption-desorption isotherms

Comparative analysis of the effect of inorganic salts on the specific surface area and pore characteristics

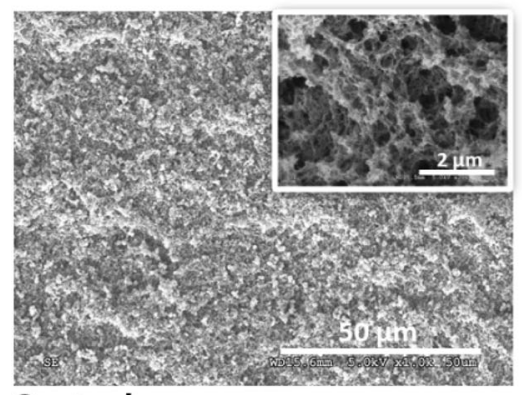

\section{Control}

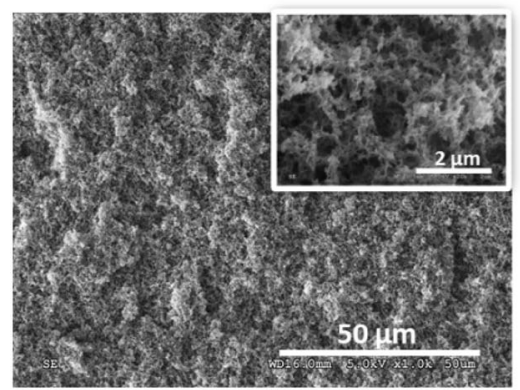

ACel-KCl

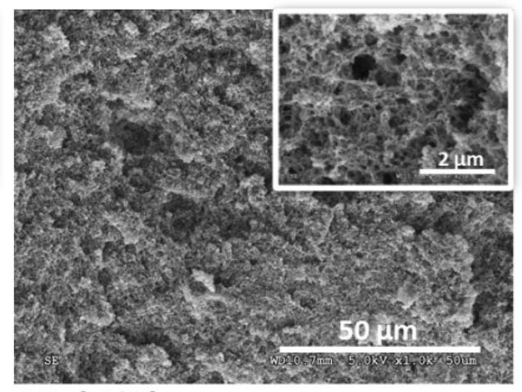

ACel-LiCl

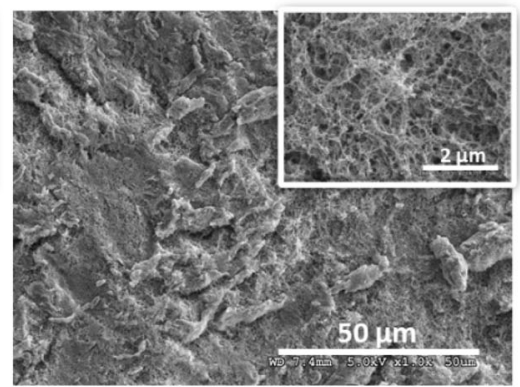

ACel- $\mathrm{MgCl}_{2}$

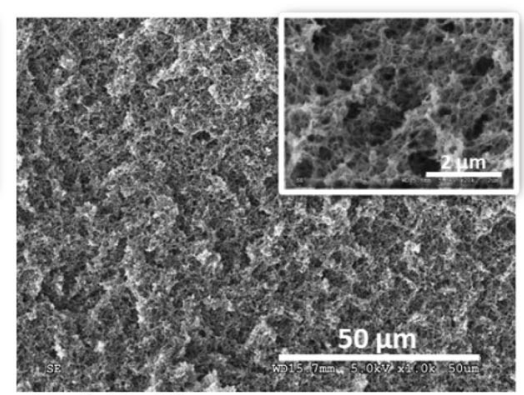

ACel-NaCl

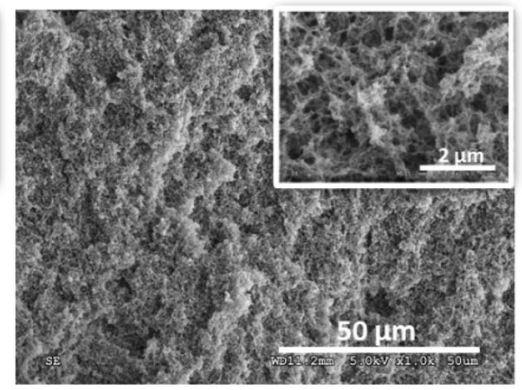

ACel- $\mathrm{CaCl}_{2}$

Fig. 4 SEM images of the cross-section of cellulose aerogels (magnification $\times 1000$, inset: magnification $\times 20,000$ ) 
(cumulative pore volume, pore diameter, and pore size distribution) of cellulose aerogels were performed using gas sorption, which allowed construction of both adsorption and desorption isotherms with the measurement of Brunauer-Emmett-Teller (BET) surface area.

Two isotherms for cellulose aerogels (control and ACel- $\mathrm{MgCl}_{2}$ ) are shown in Fig. 5. The isotherms obtained were of type IV with characteristic hysteresis loops at a high relative pressure caused by a capillary condensation in the pores, indicating the presence of pores of all types: micro-, meso-, and macropores. Monolayer adsorption was seen at low relative pressure (micro-porosity indication, $<2 \mathrm{~nm}$ ), and multilayer adsorption was observed at higher relative pressure (no-porosity or macro-porosity indication $>50 \mathrm{~nm}$ ). Thus, an apparent hysteresis loop was seen at relative pressure from 0.750 (Fig. 5), associated with capillary condensation taking place in the mesopores. The specific surface area as a function of salt types compared to the control is shown in Fig. 6a. The surface area was found to be statistically larger for all aerogels prepared with added salts $\left(146-189 \mathrm{~m}^{2} / \mathrm{g}\right)$ than for the control $\left(118 \mathrm{~m}^{2} / \mathrm{g}\right)$. The specific surface area increased from $118 \mathrm{~m}^{2} / \mathrm{g}$ to 189 $\mathrm{m}^{2} / \mathrm{g}$ upon addition of $0.5 \mathrm{wt} \% \mathrm{MgCl}_{2}$, followed by $\mathrm{LiCl}\left(177 \mathrm{~m}^{2} / \mathrm{g}\right), \mathrm{CaCl}_{2}\left(164 \mathrm{~m}^{2} / \mathrm{g}\right), \mathrm{NaCl}\left(153 \mathrm{~m}^{2} / \mathrm{g}\right)$, and $\mathrm{KCl}\left(146 \mathrm{~m}^{2} / \mathrm{g}\right)$ following the order $\mathrm{MgCl}_{2-}$ $>\mathrm{LiCl}>\mathrm{CaCl}_{2}>\mathrm{NaCl}>\mathrm{KCl}$ (Fig. 6a) which was consistent with the change in cationic radii.

The surface area values were compared with those reported by others for cellulose aerogels developed using microcrystalline cellulose, in $\mathrm{NaOH}_{\mathrm{aq}}$ solvent system, and dried using sc- $\mathrm{CO}_{2}$. However, direct

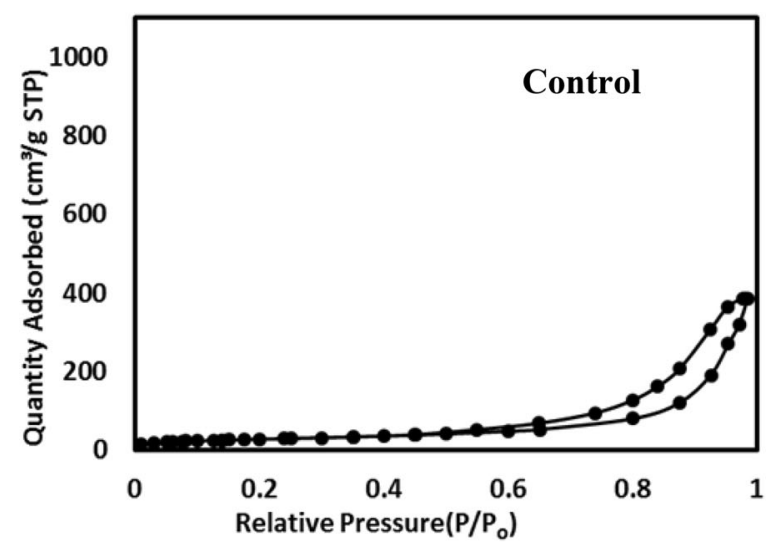

comparison of surface area was difficult, as different preparation conditions for aerogels were used by different authors. Such different $\mathrm{NaOH}$ concentrations and temperature combinations result in the formation of different cellulose- $\mathrm{NaOH}$ complexes, directly affecting cellulose dissolution, and respective hydrogels formation (Sobue et al. 1939).

Thus, Dassanayake et al. (2016) reported dissolution of cellulose at $-16{ }^{\circ} \mathrm{C}$ while stirring every $5 \mathrm{~min}$ for $1 \mathrm{~h}$, and then gelating the solution at $50{ }^{\circ} \mathrm{C}$; the process resulted in aerocelluloses with surface area of $122 \mathrm{~m}^{2} / \mathrm{g}$. The surface area was comparable with the value that we obtained for "control" aerogels in the absence of added salts $\left(118 \mathrm{~m}^{2} / \mathrm{g}\right)$. Likewise, $\mathrm{Hu}$ et al. (2016) reported the average specific surface area of aerocellulose of $124 \mathrm{~m}^{2} / \mathrm{g}$, using very similar conditions. This value is also in line with the surface area of aerogels prepared in this study. Gavillon and Budtova (Gavillon and Budtova 2008) observed a much higher specific surface area for Avicel and Solucell aerogels (240 and $260 \mathrm{~m}^{2} / \mathrm{g}$, respectively). The surface area of aerocelluloses prepared using MCC and $\mathrm{NaOH}_{\mathrm{aq}}$ in a similar condition is presented in Table 3.

The enhancement in the specific surface area could be attributed to the restriction in the normal reorganization of cellulose molecules due to the presence of cations. The cellulose interaction with the cations prevented the normal reorganization of cellulose chains during regeneration allowing cellulose to rearrange differently leading to differences in the specific surface area. The results showed that even though the addition of salts resulted in an increase of the specific surface area compared to the control in all

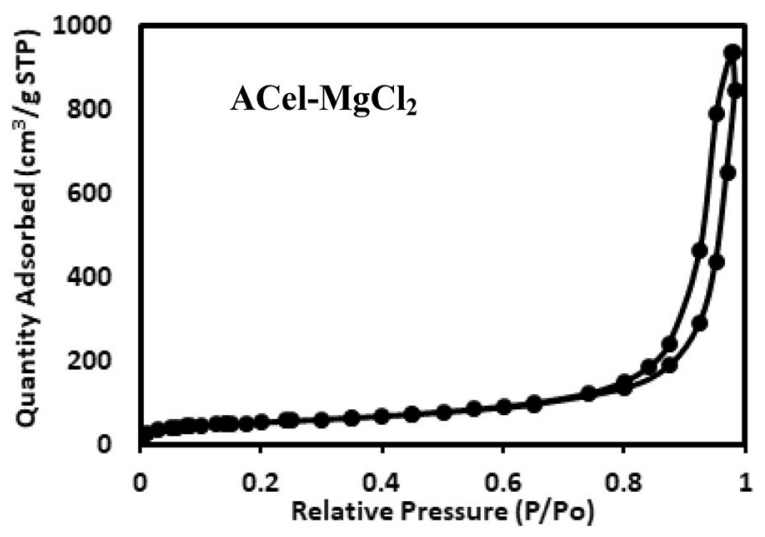

Fig. $5 \mathrm{~N}_{2}$ adsorption-desorption isotherms of aerogels (left: Control, right: $\mathrm{ACel}-\mathrm{MgCl}_{2}$ ) 

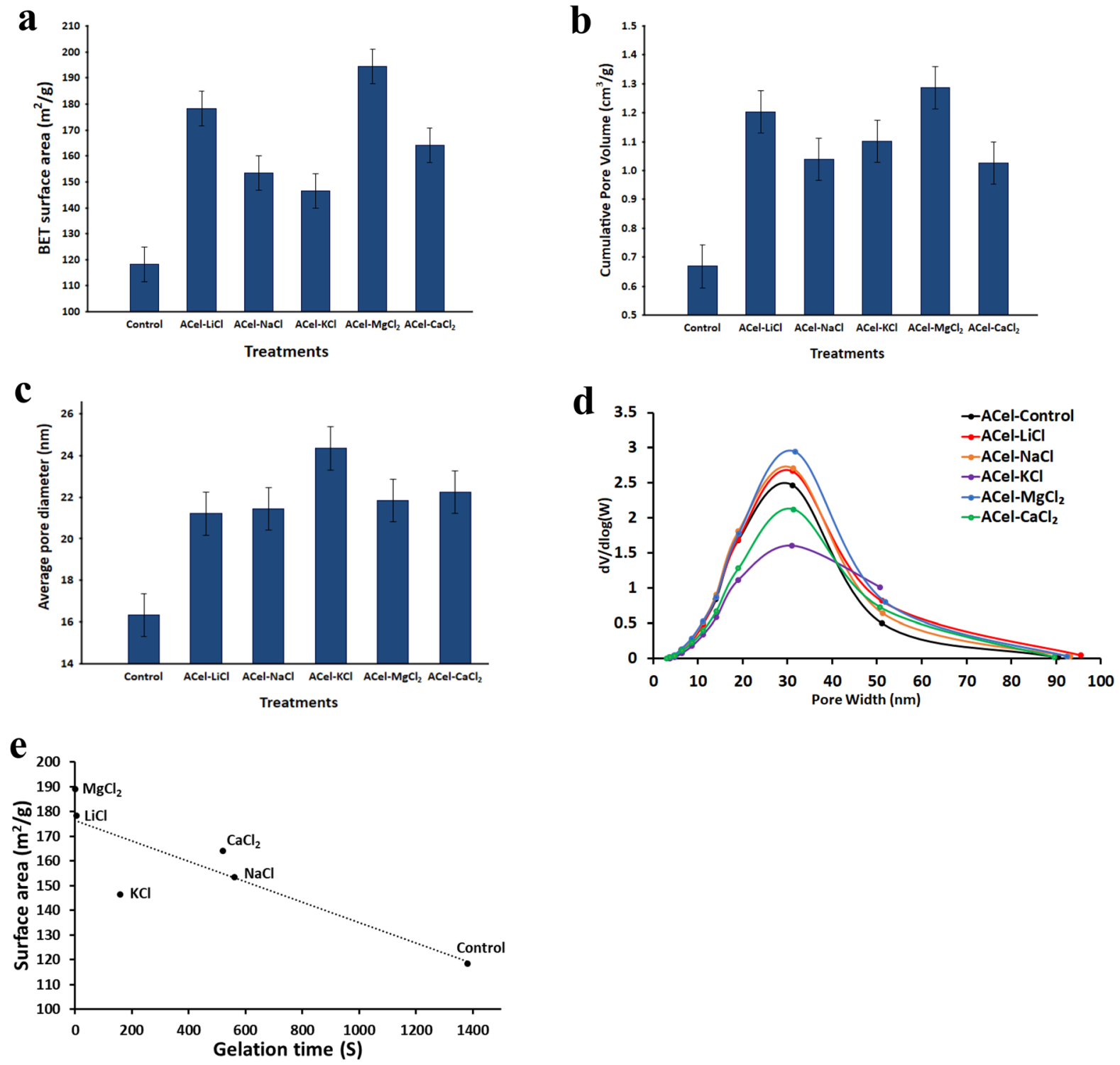

Fig. 6 Effect of salt on a BET surface area, $\mathbf{b}$ cumulative pore volume, $\mathbf{c}$ average pore diameter of cellulose aerogels, $\mathbf{d}$ pore size distribution, e relationship between the surface area and gelation time for different salts

cases, it was larger for aerogels prepared with salt having a lower cationic radius $\left(\mathrm{MgCl}_{2}\right.$ and $\left.\mathrm{LiCl}\right)$, and smaller for those with larger radii. The high specific surface area in the case of $\mathrm{MgCl}_{2}$ added aerogels could be due to the synergistic effect of the charges and cationic radii. Indeed because of the $2+$ charge of $\mathrm{Mg}^{2+}$ ion, $\mathrm{MgCl}_{2}$ had higher effect than $\mathrm{NaCl}$ and $\mathrm{LiCl}$. Moreover, the smaller size of $\mathrm{Mg}^{2+}$ is responsible for intense interaction than the bigger sized $\mathrm{K}^{+}$ with the cellulose and subsequent effect on the cellulose morphology. The smaller surface area of
ACel- $\mathrm{KCl}$ could be due to the large pore size because of their inverse relationship.

It is worth noting that the surface area of the aerogels was closely related to the gelation time. The cellulose solution with the longest gelation time yielded aerogels with the lowest surface area (i.e., control), whereas the shorter gelation time (Cel$\mathrm{MgCl}_{2}$ and Cel-LiCl) yielded a higher surface area aerogel. The change in the specific surface area is directly related to the change in the gelation time when a particular salt is added (Fig. 6e). With an increase in 
Table 3 Surface area of cellulose aerogels developed using MCC and $\mathrm{NaOH}_{\mathrm{aq}}$ solvent systems

\begin{tabular}{ccccccc}
\hline S.N & $\begin{array}{l}\text { Cellulose } \\
\text { source }\end{array}$ & Additives & Solvent & $\begin{array}{l}\text { Preparation conditions (cellulose load, } \\
\text { temperature) }\end{array}$ & $\begin{array}{l}\text { BET surface } \\
\text { area, } \mathrm{m}^{2} / \mathrm{g}\end{array}$ & References \\
\hline 1 & MCC & $\begin{array}{c}\text { Inorganic } \\
\text { salts }\end{array}$ & $\begin{array}{c}7.6 \% \mathrm{NaOH} / \\
\text { water }\end{array}$ & $5 \%,-12{ }^{\circ} \mathrm{C}$ & $146-189$ & This study \\
2 & MCC & None & $\begin{array}{c}7.6 \% \mathrm{NaOH} / \\
\text { water }\end{array}$ & $5 \%,-12{ }^{\circ} \mathrm{C}$ & 118 & Parajuli et al. (2020) \\
3 & MCC & None & $\begin{array}{c}7.6 \% \mathrm{NaOH} / \\
\text { water }\end{array}$ & $5 \%,-16{ }^{\circ} \mathrm{C}$ & 122 & $\begin{array}{c}\text { Dassanayake et al. } \\
(2016)\end{array}$ \\
4 & MCC & None & $\begin{array}{c}7.6 \% \mathrm{NaOH} / \\
\text { water }\end{array}$ & $5 \%,-12{ }^{\circ} \mathrm{C}$ & 124 & Hu et al. (2016) \\
6 & MCC & None & $\begin{array}{c}7.6 \% \mathrm{NaOH} / \\
\text { Water }\end{array}$ & $5 \%,-6{ }^{\circ} \mathrm{C}$ & 240 & $\begin{array}{c}\text { Gavillon and } \\
\text { Budtova (2008) }\end{array}$ \\
\hline
\end{tabular}

the gelation time, there was a gradual decrease in the specific surface area. The observed correlation between the gelation time and the specific surface area of aerogels could be rationalized by faster gel formation that gives less time for the cellulose macromolecules to get organized into an ordered structure. This might lead to aerogels with rough, porous structures, and higher surface area. Therefore, in this study the gelation time could be used as a predictor of the specific surface area.

Cumulative pore volume

Cumulative pore volume, the total volume of the pores, is another critical internal morphology characteristic of aerogels. The pore size was estimated from the isotherms of aerogels and ranged from a few $\mathrm{nm}$ to $\sim 50 \mathrm{~nm}$, demonstrating the presence of micro-, meso-, and macro-pores. The average pore size was the highest for ACel-KCl (ca. $25 \mathrm{~nm}$ ) and the lowest for ACel-LiCl (ca. $21 \mathrm{~nm}$ ). It was evident (Fig. 6b) that the cumulative pore volume was affected by salt types. The total pore volume was the highest for ACel$\mathrm{MgCl}_{2}$, followed by ACel-LiCl, ACel-KCl, ACel$\mathrm{NaCl}$, and Acel- $\mathrm{CaCl}_{2}$. The lower pore volume for $\mathrm{ACel}-\mathrm{KCl}$ could be attributed to bigger pore size and broader pore size distribution. In contrast, the salt with smaller pore size resulted in a higher total pore volume.
Powder X-ray diffraction (pXRD)

To obtain a better understanding of the effect of salt particles on the cellulose crystalline structure, pXRD patterns of the aerogels with a series of salts were examined (Fig. 7).

In all cases, the pXRD patterns of aerogels revealed the presence of six major diffraction peaks at $2 \theta$ values of $12^{\circ}, 20^{\circ}, 21.7^{\circ}, 28.5^{\circ}, 34.5^{\circ}$, and $40.9^{\circ}$, suggesting that cellulose existed in cellulose II crystalline form, thermodynamically more stable one, of lower crystallinity (Oh et al. 2005). No peaks associated with $\mathrm{NaCl}$ (Addala et al. 2013), $\mathrm{KCl}$ (Bouhdjer et al. 2013), $\mathrm{LiCl}$ (Xu et al. 2017), $\mathrm{MgCl}_{2}$ (Thushara et al. 2012), nor $\mathrm{CaCl}_{2}$ (Swanson et al. 1974) were present in the diffractograms, likely due to high solubility of salts that we used in water, and large amount of water used for regeneration and washing of hydrogels. Among these peaks, the three important peaks at $12^{\circ}, 20^{\circ}$, $21.7^{\circ}$ have miller indices of $\left(\begin{array}{lll}1 & -1 & 0\end{array}\right),\left(\begin{array}{lll}1 & 1 & 0\end{array}\right)$ and $\left(\begin{array}{ll}0 & 2\end{array}\right.$ $0)$ respectively (French 2014). There was no major difference between pXRD patterns of the aerogels prepared with the addition of different salts although some changes in the crystallinity index $(\mathrm{CI})$ and the crystallite size were observed. It was found that the control samples were of higher crystallinity and crystallite size. Similar values for crystallinity and crystallite size (for 1-1 0 peak) were reported previously for cellulose treated with 7.5\% NaOH (Nomura et al. 2020). Aerogels prepared from cellulose solutions with divalent salts have a lower CI and crystallite size than those made with added monovalent salts. The crystallinity was proportional and the crystallite size 


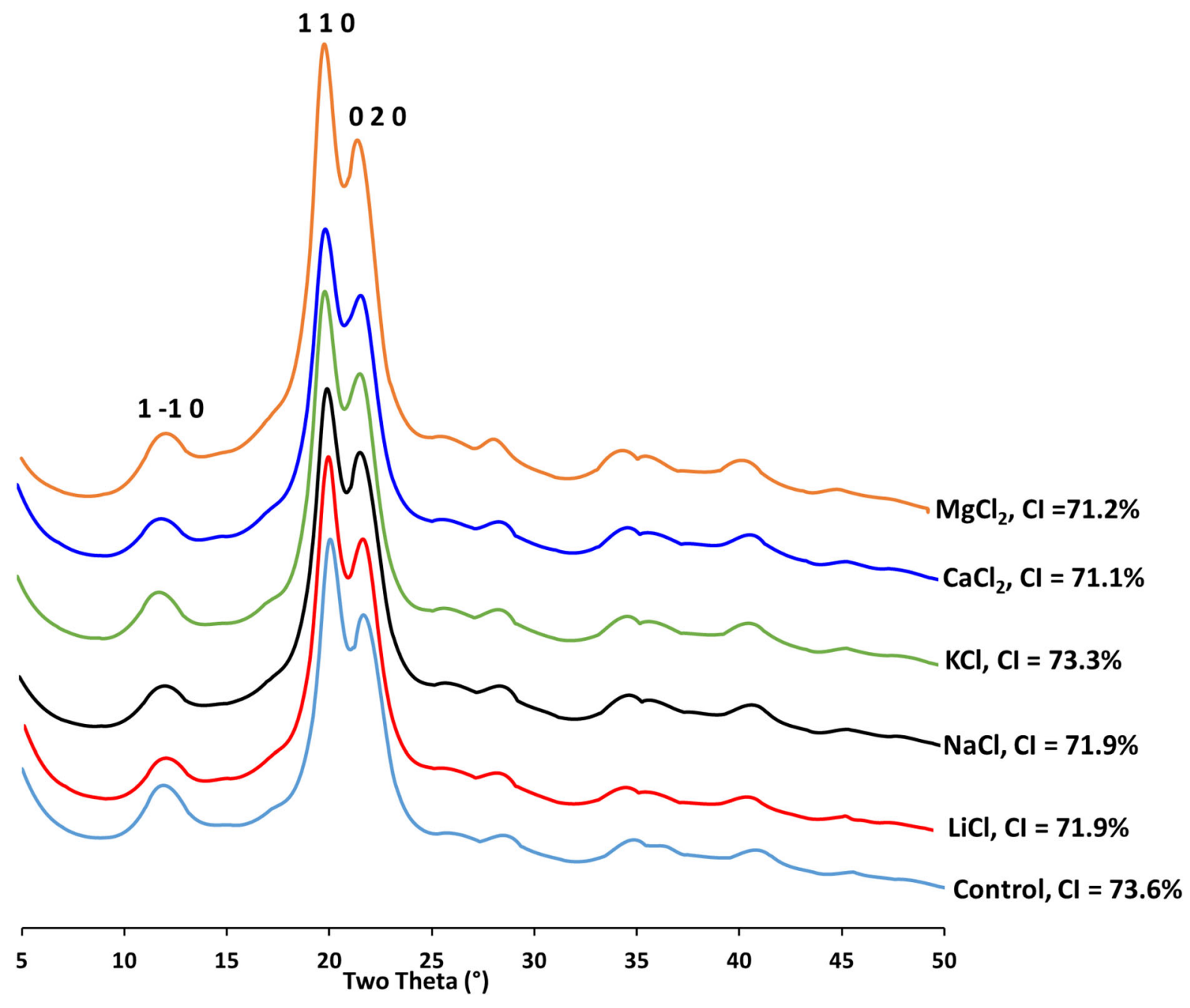

Fig. 7 pXRD pattern of the aerogels with different salts

inversely proportional to cationic radii for monovalent salts (Table 4).

pXRD results corroborated the likely role of salts in preventing the formation of ordered cellulose domains or aggregates. The difference in CI value for aerogels with different salts could be attributed to the variation in their cationic radii which determined the extent of interaction between salt hydrates and cellulose hydrates.

Thermal gravimetric analysis (TGA)

Further examination of different aerocelluloses was conducted by thermal gravimetric analysis (TGA). TGA curves and thermogravimetric derivative (DTG)
Table 4 Crystallinity index (CI) and the Crystallite size of the aerogels with different salts

\begin{tabular}{lll}
\hline Aerogels & CI $(\%)$ & Crystallite size $(\mathrm{nm})$ \\
\hline Control & $\sim 74$ & 4.91 \\
ACel-LiCl & $\sim 72$ & 4.74 \\
ACel-NaCl & $\sim 72$ & 4.71 \\
ACel-KCl & $\sim 73$ & 4.53 \\
ACel- $\mathrm{MgCl}_{2}$ & $\sim 71$ & 3.95 \\
ACel-CaCl & $\sim 71$ & 6.42 \\
\hline
\end{tabular}

curves of the series of aerocelluloses are shown in Fig. 8. In all cases, TGA showed a two-steps decomposition, where 1 st step $\left(40-100{ }^{\circ} \mathrm{C}\right)$ was attributed to 
the removal of volatiles (7-9\%, traces of water and/or acetone), and the 2nd decomposition step (ca. $240-450{ }^{\circ} \mathrm{C}$ ) was attributed to the disintegration of cellulose $(80 \%)$.

TGA thermograms of cellulose aerogels showed that all salt-assisted aerogels displayed better thermal stability than the control. Namely, the aerocelluloses $\mathrm{ACel}-\mathrm{LiCl}$ and $\mathrm{ACel}-\mathrm{MgCl}_{2}$ exhibited the highest decomposition temperature $\left(369\right.$ and $366{ }^{\circ} \mathrm{C}$, respectively) followed by $\mathrm{ACel}-\mathrm{CaCl}_{2}\left(361{ }^{\circ} \mathrm{C}\right), \mathrm{ACel}-\mathrm{NaCl}$ $\left(354^{\circ} \mathrm{C}\right)$, ACel- $\mathrm{KCl}\left(351^{\circ} \mathrm{C}\right)$, and finally control $\left(349{ }^{\circ} \mathrm{C}\right)$. Overall, the data showed that for both monovalent salts and divalent salts, lower cationic radii imparted better thermal stability to the aerocellulose.

Impact of ionic additives on cellulose

Investigating the potential impact of ionic additives, it is worth noticing kosmotropic and chaotropic effect of the ions that were utilized. It is known that kosmotropes reinforce whereas chaotropes break the hydrogen-bonded network of water molecules (Luo et al. 2020). Thus, kosmotropic sodium and lithium ions are small but strongly hydrated whereas potassium (also known as chaotropic ion) is larger but weakly hydrated (Liu et al. 2017). Similarly, $\mathrm{Mg}^{2+}$ and $\mathrm{Ca}^{2+}$ ions are small and strongly hydrated (Liu et al. 2017; Wiggins 2002). When salts are added into the aqueous system, they dissociate into cation and anion with strong hydration of ions (Xiong et al. 2013), and in metal chloride solutions, it is usually the

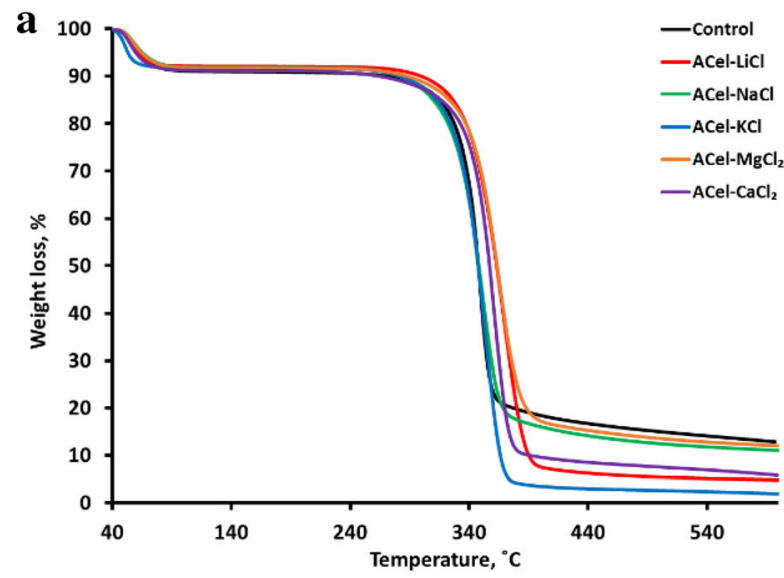

cations that determine the net behavior of the salt (Ma and Pawlik 2007).

The ability of hydrated ions to form a stable complex with cellulose and the number of free H-bonded water affect the properties of cellulose solution. Moreover, both the charge and the radii of hydration play an important role in stabilizing the solution and determine the properties of cellulose hydrogels. $\mathrm{Li}^{+}$ has the smallest ionic radius followed by $\mathrm{Na}^{+}$and $\mathrm{K}^{+}$. In contrast, the radius of hydration is the largest for $\mathrm{Li}^{+}$followed by $\mathrm{Na}^{+}$and $\mathrm{K}^{+}$(Table 2 ). The decreasing radii of hydration is an indication of the decreasing strength of the interaction between cations and water (Waluyo et al. 2011).

Therefore, smaller cations (such as $\mathrm{Li}^{+}$and $\mathrm{Mg}^{2+}$ ) can combine with water molecules more tightly to form two hydration shells (the first tight hydration and second loose hydration) leaving no or little water to hydrate the polymer chains (Xiong et al. 2013). This makes polymer-polymer interactions more favorable than polymer-solvent interactions most probably favoring faster gel formation. In the case of $\mathrm{K}^{+}$, only loose hydration shell is formed with weak hydration ions because of larger ionic radii (Xiong et al. 2013). The bound water can easily exchange with water in the bulk and more free water is available. This condition is typically unfavorable to form a complex with cellulose. This means it cannot break existing hydrogen bonds in cellulose easily, however, it can swell cellulose (Xiong et al. 2013). Similarly, in the case of multivalent ions such as $\mathrm{Mg}^{2+}$, the small size and its high charge density result in stronger interaction with

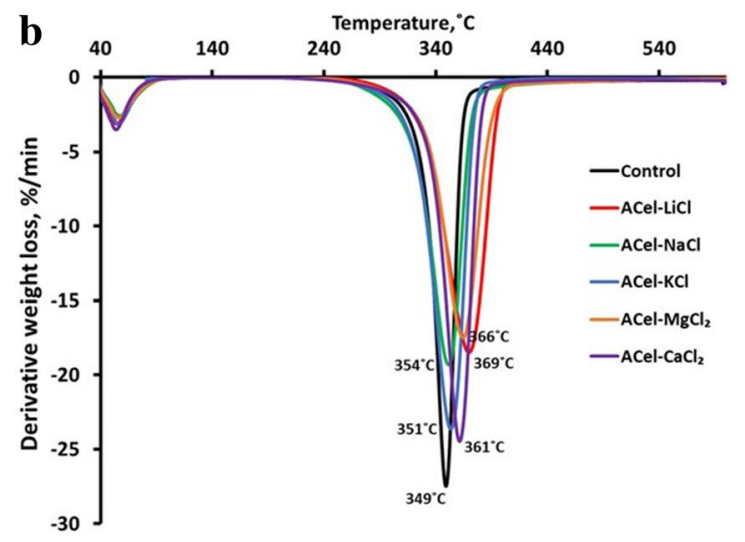

Fig. 8 TGA thermograms of cellulose aerogels. a TGA curves and b DTG curves of aerogels with different salt particles 
water molecules (Waluyo et al. 2011) and effectuates similarly to the smaller sized cations as described above.

\section{Conclusions}

In this work, we studied the effect of the addition of various inorganic salts $\left(\mathrm{LiCl}, \mathrm{NaCl}, \mathrm{KCl}, \mathrm{MgCl}_{2}\right.$, and $\mathrm{CaCl}_{2}$ ) on the ability to form cellulose monoliths, solgel transition of cellulose solutions, and resulting aerocelluloses' morphology (porosity, density, specific surface area, total pore volume and pore size distribution). When $0.5 \mathrm{wt} \%$ of solid salts were introduced to the cellulose solution prior to gelation stage, the gelation ability increased (i.e., gels were formed faster and at lower temperature) but when the concentration reached or even exceeded a certain limit, different for different salts, the gelation ability declined. This maximum salt concentration that allowed monolith formation was higher for monovalent salts than for divalent salts. The rheological study showed that the sol-gel transition in pure cellulose solution and cellulose/salt solution mixture was a function of time and temperature. Compared to pure cellulose solution, the critical gel point of cellulose/ salt solutions occurred at much shorter time. The gelation of the cellulose solution with the smallest size cations $\left(\mathrm{Li}^{+}, \mathrm{Mg}^{2+}\right)$ occurred immediately, and with the largest size cations took relatively longer time, following the order: Control $>\mathrm{Cel}-\mathrm{NaCl}>\mathrm{Cel}-$ $\mathrm{CaCl}_{2}>$ Cel-KCl $>$ Cel-LiCl $\sim$ Cel- $\mathrm{MgCl}_{2}$.

The microarchitectural study showed that the salt addition improved the porosity, with the salt with largest cationic radii $(\mathrm{KCl})$ inducing the highest porosity. The same was confirmed with SEM, where images showed that control aerogel exhibited more compact structure compared to a more open porous structure (with the presence of micro-, meso-, and macro-pores) for aerogels prepared with added salt, and the average pore size $20-25 \mathrm{~nm}$. The surface area was found to be statistically higher for all aerogels prepared with added salts $\left(146-189 \mathrm{~m}^{2} / \mathrm{g}\right)$ than for the control $\left(118 \mathrm{~m}^{2} / \mathrm{g}\right)$ following the order $\mathrm{MgCl}_{2}$ $>\mathrm{LiCl}>\mathrm{CaCl}_{2}>\mathrm{NaCl}>\mathrm{KCl}$. With the same concentration, salts with the lowest cationic radius $\left(\mathrm{MgCl}_{2}\right)$ yielded cellulose aerogels with $\sim 30 \%$ higher specific surface area than the salt with the highest cationic radius $(\mathrm{KCl})$.
pXRD analysis showed that the aerogels prepared from solutions with divalent salts had a lower crystallinity than those prepared with the assistance of monovalent salts, and all of aerogels were of lower crystallinity than aerogels prepared with no added salt (control). TGA analysis showed that aerogels with higher specific surface area showed $\sim 20{ }^{\circ} \mathrm{C}$ improvement in the thermal stability than those with lower specific surface area. All of this shows that the physicochemical properties of aerogels could be tailored by using inorganic salts of specific properties.

Acknowledgments The authors would like to thank Dr. Bo Zhao of the College of Arts and Sciences Microscopy at Texas Tech University for her help in SEM images collection. Partial funding was provided by Cotton Incorporated and Texas State Support Committee.

\section{Declarations}

\section{Conflict of interest None.}

Ethical standards This study was conducted following Compliance with Ethical Standards, and it did not involve human participants, animals, and potential conflicts of interest.

Open Access This article is licensed under a Creative Commons Attribution 4.0 International License, which permits use, sharing, adaptation, distribution and reproduction in any medium or format, as long as you give appropriate credit to the original author(s) and the source, provide a link to the Creative Commons licence, and indicate if changes were made. The images or other third party material in this article are included in the article's Creative Commons licence, unless indicated otherwise in a credit line to the material. If material is not included in the article's Creative Commons licence and your intended use is not permitted by statutory regulation or exceeds the permitted use, you will need to obtain permission directly from the copyright holder. To view a copy of this licence, visit http://creativecommons.org/licenses/by/4.0/.

\section{References}

Addala S, Bouhdjer L, Chala A, Bouhdjar A, Halimi O, Boudine B, Sebais M (2013) Structural and optical properties of a $\mathrm{NaCl}$ single crystal doped with $\mathrm{CuO}$ nanocrystals. Chin Phys B 22(9):098103

Barrett EP, Joyner LG, Halenda PP (1951) The determination of pore volume and area distributions in porous substances. I. Computations from nitrogen isotherms. J Am Chem Soc 73:373-380. https://doi.org/10.1021/ja01145a126

Bouhdjer L, Addala S, Chala A, Halimi O, Boudine B, Sebais M (2013) Elaboration and characterization of a $\mathrm{KCl}$ single crystal doped with nanocrystals of a $\mathrm{Sb} 2 \mathrm{O} 3$ semiconductor. J Semicond 34(4):043001. https://doi.org/10.1088/16744926/34/4/043001 
Brunauer S, Emmett PH, Teller E (1938) Adsorption of Gases in Multimolecular Layers. J Am Chem Soc 60:309-319. https://doi.org/10.1021/ja01269a023

Buchtová N, Budtova T (2016) Cellulose aero-, cryo- and xerogels: towards understanding of morphology control. Cellulose 23:2585-2595. https://doi.org/10.1007/s10570016-0960-8

Budtova T (2019) Cellulose II aerogels: a review. Cellulose 26:81-121. https://doi.org/10.1007/s10570-018-2189-1

Budtova T, Navard P (2016) Cellulose in $\mathrm{NaOH}$ - water based solvents: a review. Cellulose 23:5-55. https://doi.org/10. 1007/s10570-015-0779-8

Cai H, Sharma S, Liu W, Mu W, Liu W, Zhang X, Deng Y (2014) Aerogel microspheres from natural cellulose nanofibers and their application as cell culture scaffold. Biomacromol 15(7):2540-2547. https://doi.org/10.1021/ bm5003976

Cai J, Zhang L (2006) Unique gelation behavior of cellulose in $\mathrm{NaOH} /$ urea aqueous solution. Biomacromol 7:183-189. https://doi.org/10.1021/bm0505585

Chin SF, Jimmy FB, Pang SC (2016) Fabrication of cellulose aerogel from sugarcane bagasse as drug delivery carriers. J Phys Sci 27:159-168

Dassanayake RS, Gunathilake C, Jackson T, Jaroniec M, Abidi N (2016) Preparation and adsorption properties of aerocellulose-derived activated carbon monoliths. Cellulose 23:1363-1374. https://doi.org/10.1007/s10570-016-08861

French AD (2014) Idealized powder diffraction patterns for cellulose polymorphs. Cellulose 21:885-896. https://doi. org/10.1007/s10570-013-0030-4

French AD, Cintron MS (2013) Cellulose polymorphy, crystallite size, and the segal crystallinity index. Cellulose 20:583-588. https://doi.org/10.1007/s10570-012-9833-y

Ganesan K, Barowski A, Ratke L, Milow B (2018) Influence of hierarchical porous structures on the mechanical properties of cellulose aerogels. J Sol-Gel Sci Technol 89:156-165. https://doi.org/10.1007/s10971-018-4828-2

Ganesan K, Dennstedt A, Barowski A, Ratke L (2016) Design of aerogels, cryogels and xerogels of cellulose with hierarchical porous structures. Mater Des 92:345-355. https:// doi.org/10.1016/j.matdes.2015.12.041

Garba ZN, Lawan I, Zhou W, Zhang M, Wang L, Yuan Z (2020) Microcrystalline cellulose (MCC) based materials as emerging adsorbents for the removal of dyes and heavy metals: a review. Sci Total Environ 717:135070. https:// doi.org/10.1016/j.scitotenv.2019.135070

Gavillon R (2007) Preparation and characterization of ultra porous cellulosic materials. Dissertation, École Nationale Supérieure des Mines de Paris

Gavillon R, Budtova T (2008) Aerocellulose: New highly porous cellulose prepared from cellulose- $\mathrm{NaOH}$ aqueous solutions. Biomacromol 9:269-277. https://doi.org/10. 1021/bm700972k

Hu Y, Li S, Jackson T, Moussa H, Abidi N (2016) Preparation, characterization, and cationic functionalization of cellulose-based aerogels for wastewater clarification. https:// www.hindawi.com/journals/jma/2016/3186589/

Joshi SC (2011) Sol-gel behavior of hydroxypropyl methylcellulose (HPMC) in ionic media including drug release.
Materials (basel) 4:1861-1905. https://doi.org/10.3390/ ma4101861

Juhasz L, Moldovan K, Gurikov P, Liebner FI, Kalmar J, Cserhati C (2021) False morphology of aerogels caused by gold coating for SEM imaging. Polymers 13(4):588. https://doi.org/10.3390/polym13040588

Kang KE, Park DH, Jeong GT, Jeong GT (2013) Effects of inorganic salts on pretreatment of Miscanthus straw. Bioresour Technol 132:160-165. https://doi.org/10.1016/j. biortech.2013.01.012

Khalil HPSA, Adnan AS, Yahya EB, Olaiya NG, Safrida S, Hossain MS, Balakrishnan V, Gopakumar DA, Abdullah CK, Oyekanmi AA, Pasquini D (2020) A review on plant cellulose nanofibre-based aerogels for biomedical applications. Polymers 12:1759. https://doi.org/10.3390/ polym 12081759

Laka M, Chernyavskaya S, Klaviens Z, Treimanis A (2001) Properties of microcrystalline cellulose gels formed in salt solutions. Cellul Chem Technol 35:409-416

Lazzari LK, Perondi D, Zampieri VB, Zattera AJ, Santana RMS (2019) Cellulose/biochar aerogels with excellent mechanical and thermal insulation properties. Cellulose 26:9071-9083. https://doi.org/10.1007/s10570-01902696-3

Li D, Wang Y, Sun Y, Lu Y, Chen S, Wang B, Zhang H, Xia Y, Yang D (2018) Turning gelidium amansii residue into nitrogen-doped carbon nanofiber aerogel for enhanced multiple energy storage. Carbon 137:31-40. https://doi. org/10.1016/j.carbon.2018.05.011

Li R, Wang S, Lu A, Zhang L (2015) Dissolution of cellulose from different sources in an $\mathrm{NaOH} /$ urea aqueous system at low temperature. Cellulose 22:339-349. https://doi.org/10. 1007/s10570-014-0542-6

Liao Q, Su X, Zhu W, Hua W, Qian Z, Liu L, Yao J (2016) Flexible and durable cellulose aerogels for highly effective oil/water separation. RSC Adv 6:63773-63781

Ling C, Chen J, Mizuno F (2013) First-principles study of alkali and alkaline earth ion intercalation in iron hexacyanoferrate: The important role of ionic radius. J Phys Chem C 117:21158-21165. https://doi.org/10.1021/jp4078689

Liu L, Kou R, Liu G (2017) Ion specificities of artificial macromolecules. Soft Matter 13(1):68-80. https://doi.org/ 10.1039/C6SM01773H

Liu L, Sun J, Cai C, Wang S, Pei H, Zhang J (2009) Corn stover pretreatment by inorganic salts and its effects on hemicellulose and cellulose degradation. Bioresour Technol 100:5865-5871. https://doi.org/10.1016/j.biortech.2009. 06.048

Long LY, Li FF, Weng YX, Wang YZ (2019) Effects of sodium montmorillonite on the preparation and properties of cellulose aerogels. Polymers (basel) 11:1-10. https://doi.org/ 10.3390/polym 11030415

Long LY, Weng YX, Wang YZ, Wang YZ (2018) Cellulose aerogels: Synthesis, applications, and prospects. Polymers (basel) 8:1-28. https://doi.org/10.3390/polym10060623

Luo P, Zhai Y, Senses E, Mamontov E, Xu G, Z Y, Faraone A, (2020) Influence of kosmotrope and chaotrope salts on wate structural relaxation. J Phys Chem Lett 11:8970-8975

Luo X, Zhang L (2010) Creation of regenerated cellulose microspheres with diameter ranging from micron to millimeter for chromatography applications. J Chromatogr A 
1217:5922-5929. https://doi.org/10.1016/j.chroma.2010. 07.026

Ma X, Pawlik M (2007) Intrinsic viscosities and Huggins constants of guar gum in alkali metal chloride solutions. Carbohydr Polym 70:15-24. https://doi.org/10.1016/j.carbpol. 2007.02.024

Mirtaghavi A, Luo J, Muthuraj R (2020) Recent advances in porous $3 \mathrm{D}$ cellulose aerogels for tissue engineering applications: a reivew. J Compos Sci 4:152. https://doi.org/10. 3390/jes4040152

Nam S, French AD, Condon BD, Concha M (2016) Segal crystallinity index revisited by the simulation of X-ray diffraction patterns of cotton cellulose I $\beta$ and cellulose II. Carbohydr Polym 135:1-9. https://doi.org/10.1016/j. carbpol.2015.08.035

Nomura S, Kugo Y, Erata T (2020) ${ }^{13} \mathrm{C}$ NMR and XRD studies on the enhancement of cellulose II crystallinity with low concentration NAOH post-treatments. Cellulose 27:3553-3563. https://doi.org/10.1007/s10570-02003036-6

Oğuz OD, Ege D (2018) Rheological and mechanical properties of thermoresponsive methylcellulose/calcium phosphatebased injectable bone substitutes. Materials (basel. https:// doi.org/10.3390/ma11040604

Oh SY, Dong IY, Shin Y, Kim HC, Kim HY, Chung YS, Park WH, Youk JH (2005) Crystalline structure analysis of cellulose treated with sodium hydroxide and carbon dioxide by means of X-ray diffraction and FTIR spectroscopy. Carbohydr Res 340:2376-2391. https://doi.org/10.1016/j. carres.2005.08.007

Parajuli P, Acharya S, Hu Y, Abidi N (2020) Cellulose-based monoliths with enhanced surface area and porosity. J Appl Polym Sci 137:48975. https://doi.org/10.1002/app.48975

Phan-Xuan T, Thuresson A, Skepö M, Labrador A, Bordes R, Matic A (2016) Aggregation behavior of aqueous cellulose nanocrystals: the effect of inorganic salts. Cellulose 23:3653-3663. https://doi.org/10.1007/s10570-016-10801

Pircher N, Carbajal L, Schimper C, Bacher M, Rennhofer H, Nedelec J-M, Lichtenegger HC, Rosenau T, Liebner F (2016) Impact of selected solvent systems on the pore and solid structure of cellulose aerogels. Cellulose 23:1949-1966. https://doi.org/10.1007/s10570-016-0896$\mathrm{Z}$

Pircher N, Fischhuber D, Carbajal L, Strauß C, Nedelec J-M, Kasper C, Rosenau T, Liebner F (2015) Preparation and reinforcement of dual-porous biocompatible cellulose scaffolds for tissue engineering. Macromol Mater Eng 300:911-924. https://doi.org/10.1002/mame.201500048

Scherrer P (1912) Bestimmung der inneren Struktur und der Größe von Kolloidteilchen mittels Röntgenstrahlen. Kolloidchemie Ein Lehrbuch. Springer, Berlin, pp 387-409

Schestakow M, Karadagli I, Ratke L (2016a) Cellulose aerogels prepared from an aqueous zinc chloride salt hydrate melt. Carbohydr Polym 137:642-649. https://doi.org/10.1016/j. carbpol.2015.10.097

Schestakow M, Muench F, Reimuth C, Ratke L, Ensinger W (2016b) Electroless synthesis of cellulose-metal aerogel composites. Appl Phys Lett 108:213108. https://doi.org/ $10.1063 / 1.4952948$
Segal L, Creely JJ, Martin AE, Conrad CM (1959) Empirical method for estimating the degree of crystallinity of native cellulose using the X-ray diffractometer. Textile Res J 29:786-794. https://doi.org/10.1177/ 004051755902901003

Sehaqui H, Zhou Q, Berglund LA (2011) High-porosity aerogels of high specific surface area prepared from nanofibrillated cellulose (NFC). Compos Sci Technol 71:1593-1599. https://doi.org/10.1016/j.compscitech.2011.07.003

Sescousse R, Gavillon R, Budtova T (2011) Wet and dry highly porous cellulose beads from cellulose- $\mathrm{NaOH}$-water solutions: Influence of the preparation conditions on beads shape and encapsulation of inorganic particles. J Mater Sci 46:759-765. https://doi.org/10.1007/s10853-010-4809-5

Sobue H, Kiessig H, Hess K (1939) The cellulose-sodium hydroxide-water system as a function of the temperature. Z Physik Chem B 43:309-328

Shannon RD (1976) Revised effective ionic radii and systematic studies of interatomic distances in halides and chalcogenides. Acta Crystallogr Sect A 32:751-767. https://doi. org/10.1107/S0567739476001551

Swanson HE, MCMurdie HF, Morris MC, Evans EH, Paretzkin B (1974) Standard X-ray Diffraction Powder Patterns: Section 11- data for 70 Substances. 25 Department of Commerce, National Bureau of Standards, Institute for Materials Research

Thushara KS, Gnanakumar ES, Mathew R, Ajithkumar TG, Rajamohanan PR, Bhaduri S, Gopinath CS (2012) $\mathrm{MgCl}_{2} \cdot 4\left(\left(\mathrm{CH}_{3}\right)_{2} \mathrm{CHCH}_{2} \mathrm{OH}\right)$ : a new molecular adduct for the preparation of $\mathrm{TiCl}_{\mathrm{x}} / \mathrm{MgCl}_{2}$ catalyst for olefin polymerization. Dalton Trans 41(37):11311-11318

Tian J, Peng D, Wu X, Li W, Deng H, Liu S (2017) Electrodeposition of Ag nanoparticles on conductive polyaniline/cellulose aerogels with increased synergistic effect for energy storage. Carbohydr Polym 156:19-25. https://doi. org/10.1016/j.carbpol.2016.09.005

Tokuyasu K, Tabuse M, Miyamoto M, Matsuki J, Yoza K (2008) Pretreatment of microcrystalline cellulose flakes with $\mathrm{CaCl}_{2}$ increases the surface area, and thus improves enzymatic saccharification. Carbohydr Res 343:1232-1236. https://doi.org/10.1016/j.carres.2008.03. 007

Tung CYM, Dynes PJ (1982) Relationship between viscoelastic properties and gelation in thermosetting systems. J Appl Polym Sci 27:569-574. https://doi.org/10.1002/app.1982. 070270220

Volkov AG, Paula S, Deamer DW (1997) Two mechanisms of permeation of small neutral molecules and hydrated ions across pholpholipid bilayers. Bioelectrochem Bioenerg 42(2):153-160. https://doi.org/10.1016/S03024598(96)05097-0

Waluyo I, Huang C, Nordlund D, Bergmann U, Weiss TM, Pettersson LGM, Nilsson A (2011) The structure of water in the hydration shell of cations from $\mathrm{x}$-ray raman and small angle $\mathrm{x}$-ray scattering measurements. The J Chem Phys 134:064513. https://doi.org/10.1063/1.3533958

Wan C, Jiao Y, Sun Q, Li J (2016) Preparation, characterization, and antibacterial properties of silver nanoparticles embedded into cellulose aerogels. Polym Compos 37:1137-1142 
Wang X, Zhang Y, Jiang H, Song Y, Zhou Z, Zhao H (2017) Tert-butyl alcohol used to fabricate nano-cellulose aerogels via freeze-drying technology. Mater Res Express 4:065006. https://doi.org/10.1088/2053-1591/aa72bc

Wei Z, Wang T (2013) Preparation of cellulose aerogel by the salt-induced gelation. Chin J Process Eng 13:351-355

Wiggins PM (2002) Enzyme reactions and two-state water. J Biol Phys Chem 2:25-37

Winter HH, Chambon F (1986) Analysis of linear viscoelasticity of a crosslinking polymer at the gel point. J Rheol 30:367-382. https://doi.org/10.1122/1.549853

Woehl TJ, Heatley KL, Dutcher CS, Talken NH, Ristenpart WD (2014) Electrolyte-dependent aggregation of colloidal particles near electrodes in oscillatory electric fields. Langmuir 30:4887-4894. https://doi.org/10.1021/ la4048243
Xiong B, Zhao P, Cai P, Zhang L, Hu K, Cheng G (2013) NMR spectroscopic studies on the mechanism of cellulose dissolution in alkali solutions. Cellulose 20:613-621. https:// doi.org/10.1007/s10570-013-9869-7

Xu S, Sun L, He J, Han H, Wang H, Fang Y, Wang Q (2017) Effect of $\mathrm{LiCl}$ on crystallization, thermal and mechanical properties of polyamide 6/wood fiber composites. Polym Compos 39(S3):E1574-E1580

Zhang XF, Ma X, Hou T, Guo K, Yin J, Wang Z, Shu L, He M, Yao J (2019) Inorganic salts induce thermally reversible and anti-freezing cellulose hydrogels. Angew Chemie - Int Ed 58:7366-7370. https://doi.org/10.1002/anie.201902578

Publisher's Note Springer Nature remains neutral with regard to jurisdictional claims in published maps and institutional affiliations. 